\title{
REPORT
}

\section{A Report on the INSEE-CESS International Conference on "Climate Change and Disasters: Challenges, Opportunities, and Responses”}

Jeena T. Srinivasan *

The Tenth Biennial Conference of the Indian Society for Ecological Economics (INSEE) on Climate Change and Disasters: Challenges, Opportunities and Responses was organized jointly with and hosted by the Centre for Economic and Social Studies (CESS), Hyderabad, in partnership with the Deutsche Gesellschaft für Internationale Zusammenarbeit GmbH (GIZ, India) and the National Institute of Rural Development and Panchayati Raj (NIRDPR). It took place in Hyderabad during November 6-8, 2019.

In the context of the increased risk of climate-related natural disasters such as floods, heatwaves, and storms, both predicted by scientific studies and recently experienced in different parts of the world and India, the objectives of the conference were to discuss the following: What are the likely impacts of climate change on human and natural systems? How will climate change affect different sectors and sections of society? What are the alternative policy options to address the risks that climate change and extreme weather events pose? The three-day conference comprised discussions on these issues across various plenary, panel, and technical sessions in addition to inaugural and valedictory sessions. Springer Nature also organized a special session on ethical publishing. The conference received considerable media coverage and hosted over 200 delegates, including a few from abroad.

\footnotetext{
* Centre for Economic and Social Studies, N. O. Campus, Begumpet, Hyderabad 500016, Telangana, India; Secretary, INSEE (2018-20); Organizing Secretary, Tenth Biennial Conference of INSEE; jeena@cess.ac.in.

Copyright (C) Srinivasan 2020. Released under Creative Commons AttributionNonCommercial 4.0 International licence (CC BY-NC 4.0) by the author.

Published by Indian Society for Ecological Economics (INSEE), c/o Institute of Economic Growth, University Enclave, North Campus, Delhi 110007.
}

ISSN: 2581-6152 (print); 2581-6101 (web).

DOI: https://doi.org/10.37773/ees.v3i2.121 
In the inaugural address, Vinod Thomas (Former Senior Vice President, World Bank) noted that India and South and Southeast Asia are not only highly vulnerable with regards the climate crisis, but are also ill-prepared to handle it. This was the perfect start to the conference, and it set the pace for the deliberations that followed. Thomas opined that countries must be prepared to tackle disasters, develop and adopt measures to reduce risks and exposure, and build resilience within the next few years.

In his presidential address, K. N. Ninan (President, INSEE) gave an illuminating presentation on the growth and development of ecological economics in India, and on climate change and disasters from an Indian perspective. The inaugural session also featured speeches by the representatives of the collaborating organizations, who reflected on climate change issues, possible solutions, information needs, decentralized approaches, and civil society initiatives aimed at mitigation and adaptation. There was also a video message from Clóvis Cavalcanti (President, ISEE), which was played at the conference.

The conference had five illuminating keynote addresses by distinguished scholars on specific sub-themes. Rajeev Ahal (GIZ, India) talked about the need to improve water security, climate resilience, and efficiency of water use in agriculture and industry. He emphasized the need for cooperation between the private and public sectors to ensure the integrated climateadapted management of water. Kirit Parikh (Integrated Research and Action for Development/IRADe, New Delhi), who spoke on the need to develop a low carbon strategy for inclusive growth, emphasized that India should focus on renewable energies and link inclusive growth requirements with factors like housing, drinking water supply, sanitation, education, healthcare, electrification, provision of cooking gas, the infant mortality rate (IMR), and fertility.

Taking a more global perspective, Thomas Sterner (University of Gothenburg, Sweden) spoke about the twin issues of climate policy efficiency and fairness/feasibility, and the policy instruments needed to prevent worsening of the environment. In his talk on climate change, forests, and biodiversity, N. H. Ravindranath (Indian Institute of Science/IISc, Bengaluru) pointed out an increase in tree mortality, ecosystem disturbances, and the effects of climate-related extremes; he stressed that many ecosystems are more vulnerable than humans. Madhu Verma (Indian Institute of Forest Management/IIFM, Bhopal) presented the economic value of the ecosystem services of 16 tiger reserves in India using a value plus approach, and emphasized the use of valuation to justify enhancing investments in conservation. 
The conference had 10 engaging and thought-provoking panel discussions. While one panel discussed the complex interlinkages of water with other critical systems such as food, energy, and the economy, and how integrated water resources management (IWRM) can contribute to climate resilience, another showed the importance of hazard vulnerability maps and planning for disaster resilient cities. The third panel discussed how cities in countries like Nepal and Bangladesh were coping with hydro-meteorological events and floods, and the role of hard and soft interventions in mitigating such disasters. A fourth panel discussed the efficacy of local self-governance and the climate change action plans initiated by panchayats in Kerala, India. Another panel discussed Martin Weitzman's contributions to environmental economics and his seminal works on climate catastrophes. The contribution of the Mahatma Gandhi National Rural Employment Guarantee Act (MGNREGA) to climate mitigation and adaptation in terms of carbon sequestration was the theme deliberated by the sixth panel. The seventh panel discussed the quantitative methods used to assess climate change impacts on agriculture, and the eighth panel considered climate change and mitigation in rainfed areas. Building climate resilience through the restoration of common lands was the theme considered by the ninth panel. The last panel discussed the findings of a climate change vulnerability assessment in the Indian Himalayan region, which experiences frequent floods, storms, and landslides; women and children in this region are amongst the most vulnerable.

Another highlight was the outreach event organized by the Intergovernmental Panel on Climate Change (IPCC) in partnership with INSEE. The IPCC authors presented the Special Reports of the IPCC and the ongoing AR6 (Sixth Assessment Report). There were presentations on the physical and scientific bases for climate systems, climate models, and projections; the impact of global warming and the importance of mitigation activities for achieving the Sustainable Development Goals; land management and the interaction of the atmosphere with land resources; and, finally, the effects of climate change on marine life and coastal livelihoods.

Further, 56 papers contributed by participants were presented in 12 technical sessions. Some papers discussed the macroeconomic dimensions of climate change, including fiscal transfers and the political economy of disaster management. Others discussed gender issues, food security, and the Sustainable Development Goals. A few papers analysed the effects of floods, recovery patterns, and the effectiveness of early warning systems, and highlighted the role of the state and civil society. Others attempted to quantify the damage caused by floods and the risks at the community level 
and on the ecosystem. There were also papers on environmental and climate justice, institutional interventions, agricultural adaptations to climate change, and the role of MGNREGA in building the adaptive capacity of rural communities, renewable energy, and infrastructure to mitigate climate change impacts.

Gopal Kadekodi (Former President, INSEE), in his valedictory address, spoke about the dynamic interlinkages between ecosystem services and their stakeholders, and the need for changes in climate strategy.

For their outstanding contributions to ecological economics, INSEE conferred the Lifetime Achievements Award on C. H. Hanumantha Rao; the title of INSEE Fellow on M. N. Murty, Ramprasad Sengupta, and Madhu Verma; and the Bina Agarwal Prize for Ecological Economics to Joan Martinez-Alier.

Public lectures by INSEE members were organized in three reputed institutions in Hyderabad as curtain-raiser events. A pre-conference workshop on "Behavioural and Environmental Economics" and a postconference workshop in association with the South Asian Network for Development and Environmental Economics (SANDEE) on "Non-market Valuation of Environmental Goods and Services", each attended by 35-40 participants, also took place.

Overall, the conference was rich in terms of the variety of topics covered as well as in participation. The delegates had many opportunities to engage in academic and social interactions and to build their networks. The cultural event showcasing Telangana folk dances and culture added colour to the conference, and the sumptuous menu included organic, millet-based ethnic food. The conference received generous financial and in-kind support from various governmental and non-governmental organizations. 